\title{
International Interdisciplinary School IRIS, June 11-16, 2018, Issyk-Kul, Kyrgyzstan
}

Daniyar Cholponbaev ${ }^{1}$, Kairat Nurbekov ${ }^{1}$, Zhenisgul Tlegenova ${ }^{2}$, Damirbek Abibillaev ${ }^{1}$, Aiperi Toktosunova ${ }^{3}$, Nuraim Zhakybalieva ${ }^{4}$, Kudaibergen Osmonaliev ${ }^{5}$ Nurlan Torokeldiev ${ }^{5}$, Adylbek Shadykanov ${ }^{6}$ Gulmira Kudaiberdieva ${ }^{7}$,Jonathan Lipton ${ }^{7,9}$, Taalaibek Kudaiberdiev ${ }^{1,7,8}$

${ }^{1}$ Scientific Research Institute of Heart Surgery and Organ Transplantation

${ }^{2}$ West Kazakhstan Marat Ospanov State Medical University, Aktobe, Kazakhstan

${ }^{3}$ National Centre of Cardiology and Internal Medicine, Bishkek, Kyrgyzstan

${ }^{4}$ Regional High Altitude Cardiology Centre, Naryn, Kyrgyzstan

${ }^{5}$ Alatoo International University, Faculty of Medicine, Bishkek, Kyrgyzstan

${ }^{6}$ International School of Medicine, Bishkek, Kyrgyzstan

${ }^{7}$ Heart, Vessels and Transplantation

${ }^{8}$ Center for Postgraduate Education and Research, Bishkek, Kyrgyzstan

${ }^{9}$ University of Tasmania, Australia

IRIS 2018 is organized by Center for Postgraduate Education and Research, Bishkek, Kyrgyzstan under patronage of the Journal of Electrocardiology and Heart Vessels and Transplantation with support of Scientific Research Institute of Heart Surgery and Organ Transplantation.

Faculty of the IRIS Issyk-Kul 2018 consisted of Gulmira Kudaiberdieva Editor-in-Chief, Heart Vessels and Transplantation, Jonathan Lipton - Associate Editor of Heart Vessels and Transplantation,University of Tasmania, Australia, Taalaibek Kudaiberdiev - Editor Heart Vessels and transplantation, Scientific Research Institute of Heart Surgery and Organ Transplantation, Center for Postgraduate Education and Research, Bishkek, Kyrgyzstan

After welcome ceremony Faculty formed three groups In each group there were participants who had the experience of the previous school IRIS2017 in Astana and Taraz, Kazakhstan (Zhenisgul Tlegenova, Kairat Nurbekov, Daniyar Cholponbaev) []. Participants with experience teaching their speciality in English at the university (Nurlan Torokeldiev, Kudaibergen Osmonaliev, Adylbek Shadykanov) and a practical cardiologist who plans to approve a research project (Damirbek Abibillaev, Nuraim Zhakybalieva Aiperi Toktosunova,).The groups had responsibility to create research projects.

All groups from the first day demonstrate the same activity in the creation of research projects. The training consists of Workshop № 1 Project selection and introduction to research proposal, Workshop №2 Research design and methods I: Study population and outcomes, Workshop№3 Research design and methods II: data collection and analysis, Workshop № 4 Research administration. Every day one of the aspects of scientific research is discussed.

Every Workshop Faculty did the introduction, then the participants worked in groups on the project, each group presented the project, then all participants and faculty discuss the project. The moderators of the sessions were the participants.

During the discussions the participants and Faculty asked questions and gave valuable recommendations for improving the projects, after the discussions the project were amended.

Faculty emphasized the value of knowledge gained from the active work, the importance of clarify the significance and hypothesis of a scientific project.

Beautiful nature, Issyk-Kul, common interests, close cultures (8 participants from Kyrgyzstan and 1 from Kazakhstan), informal and high professional skills of the faculty created a very friendly environment. Participants do not remember the evening at the Faculty home. The participants were interested in the scientific career of Gulmira and Jonathan, their completed and planned scientific projects, the history of the IRIS school, told about their successes, problems and plans for the future.

Address for Correspondence: Jenisgul Tlegenova, West Kazakhstan Marat Ospanov State Medical University, Aktobe, Kazakhstan, Email: tlegenova g@mail.ru

Received: 17.06.2018 Accepted: 17.08.2018 
Table 1. IRIS teams and their research projects

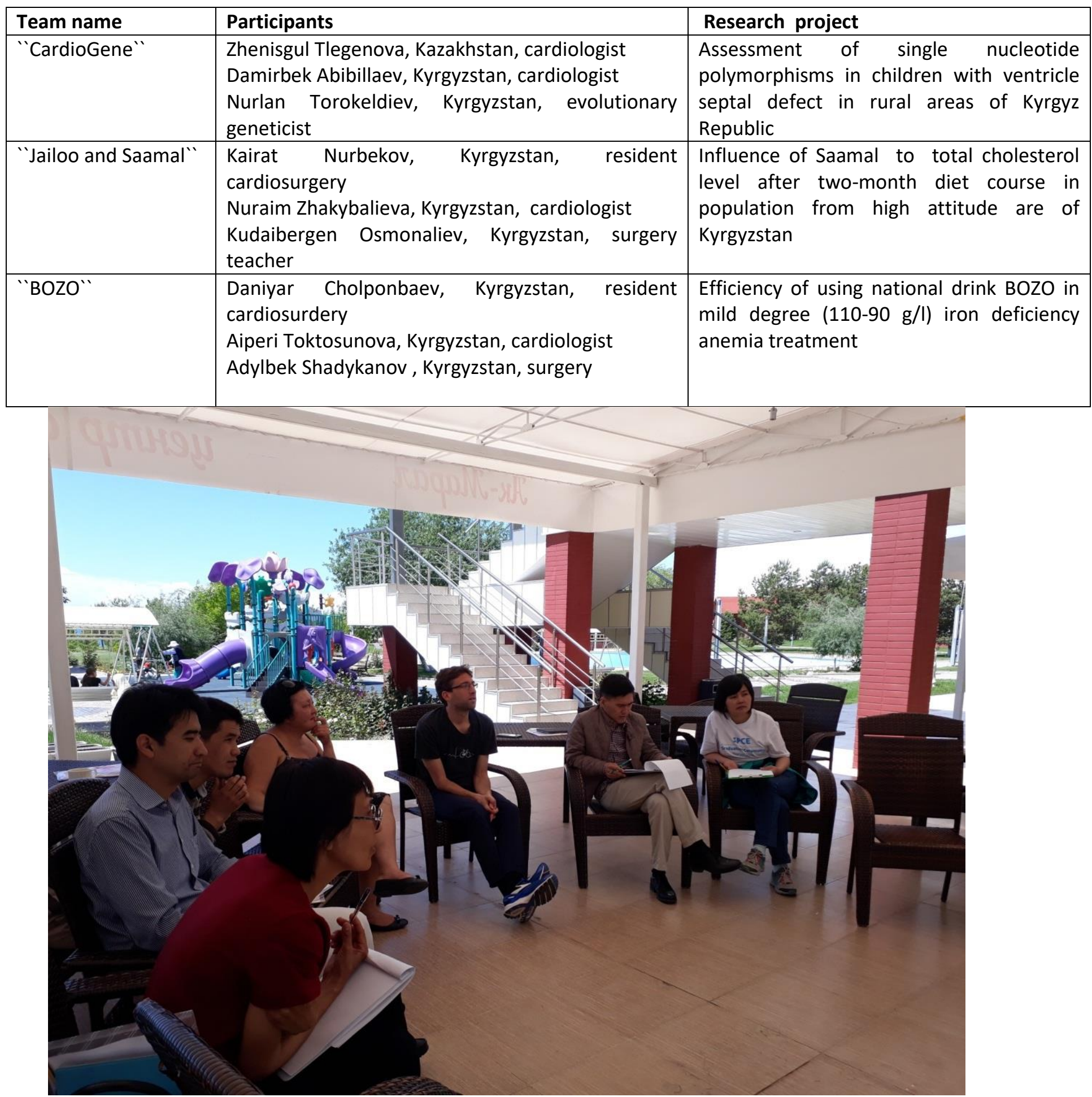

Figure 1. Discussion of the workshop: Project selection and introduction to research proposal. 


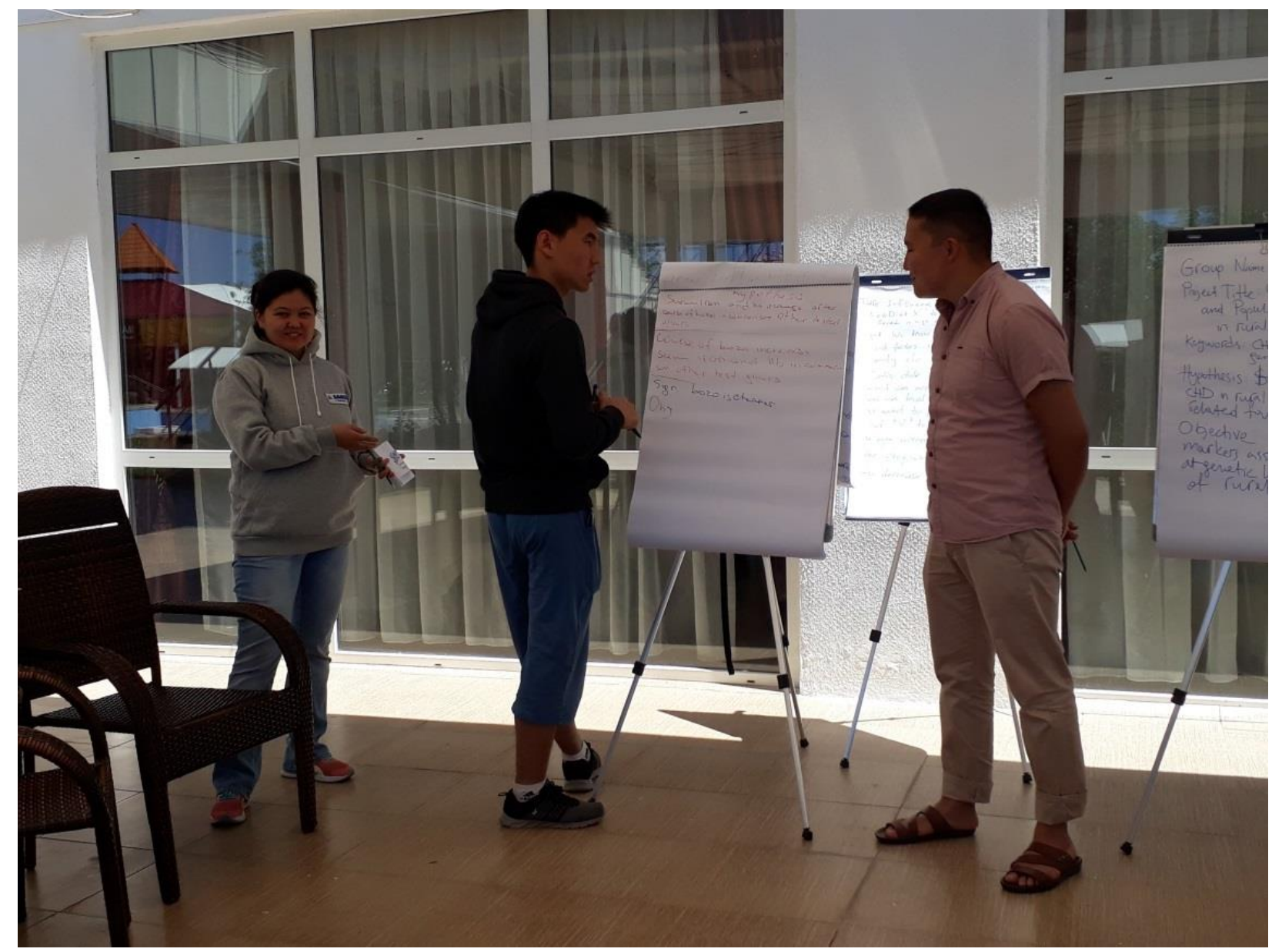

Figure 2. Performance of BOZO team: Aiperi Toktosunova, Daniyar Cholponbaev, Adylbek Shadykanov

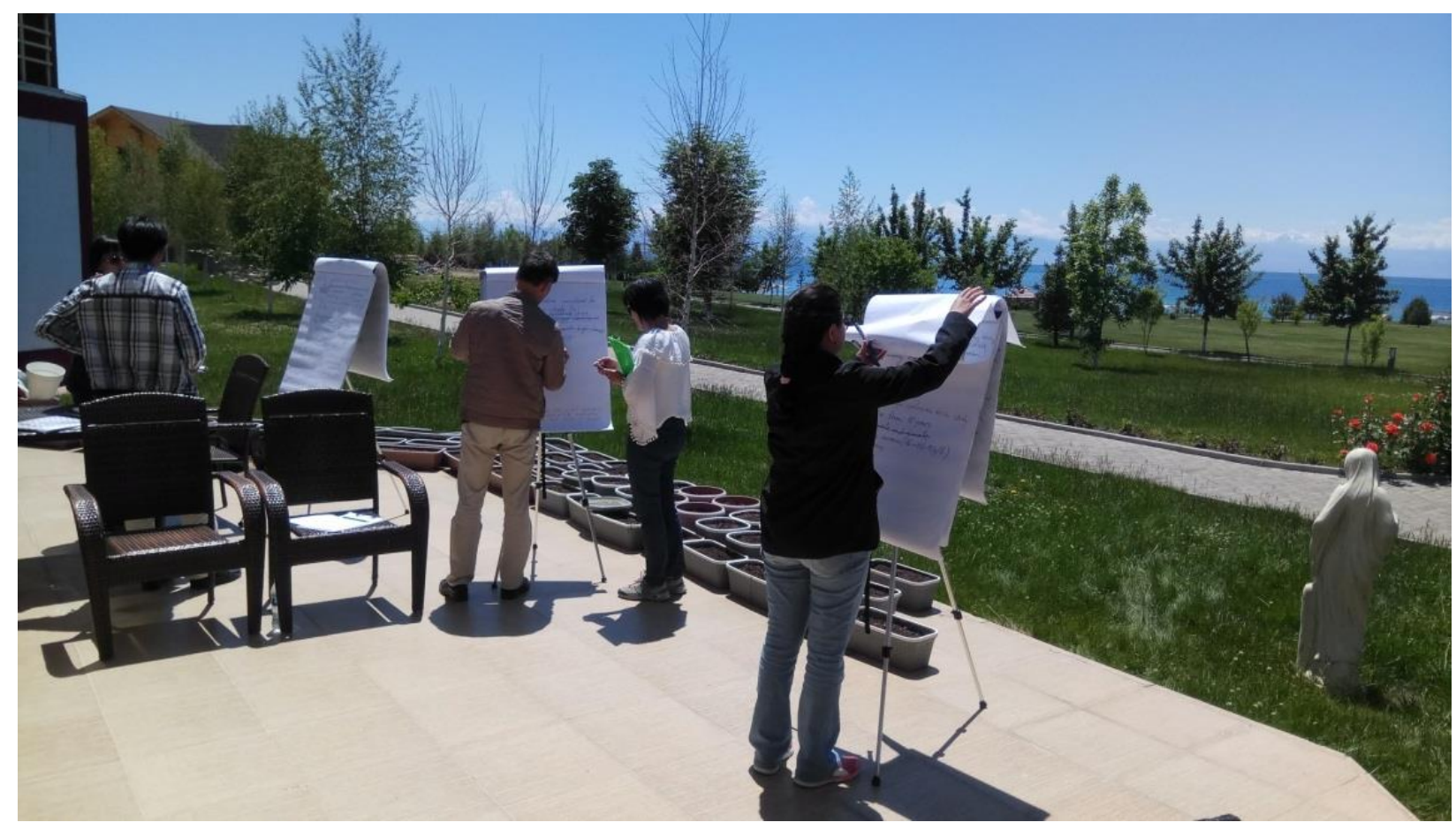

Figure 3. Working on scientific projects by teams outside. 


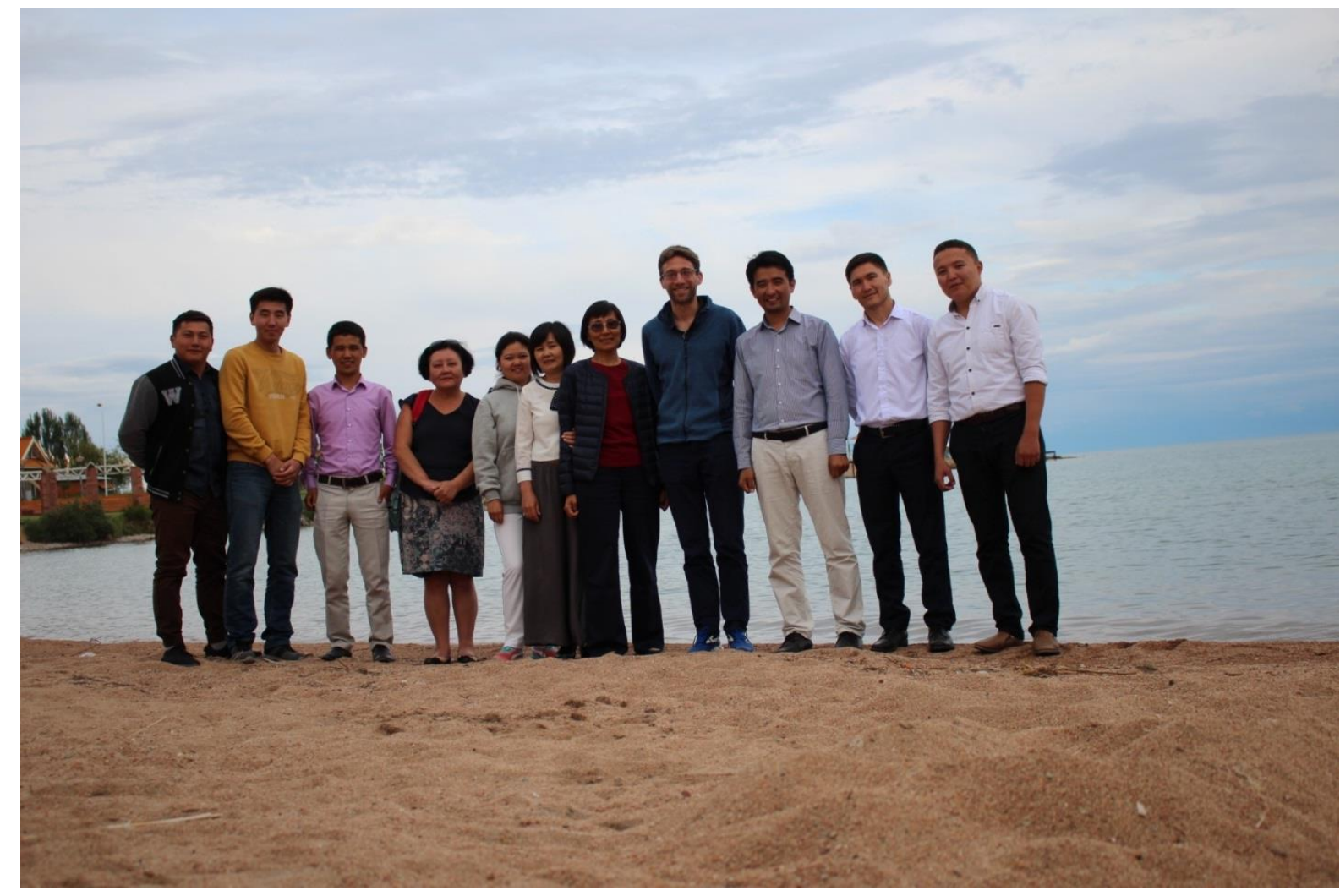

Figure 4. Participants and Faculty after intensive workshop: Kairat Nurbekov, Daniyar Cholponbaev, Damirbek Abibillaev, Gulmira Kudaiberdieva (Faculty), Aiperi Toktosunova, Nuraim Zhakybalieva, Zhenisgul Tlegenova, Jonathan Lipton (Faculty), Nurlan Torokeldiev, Kudaibergen Osmonaliev, Adylbek Shadykanov.

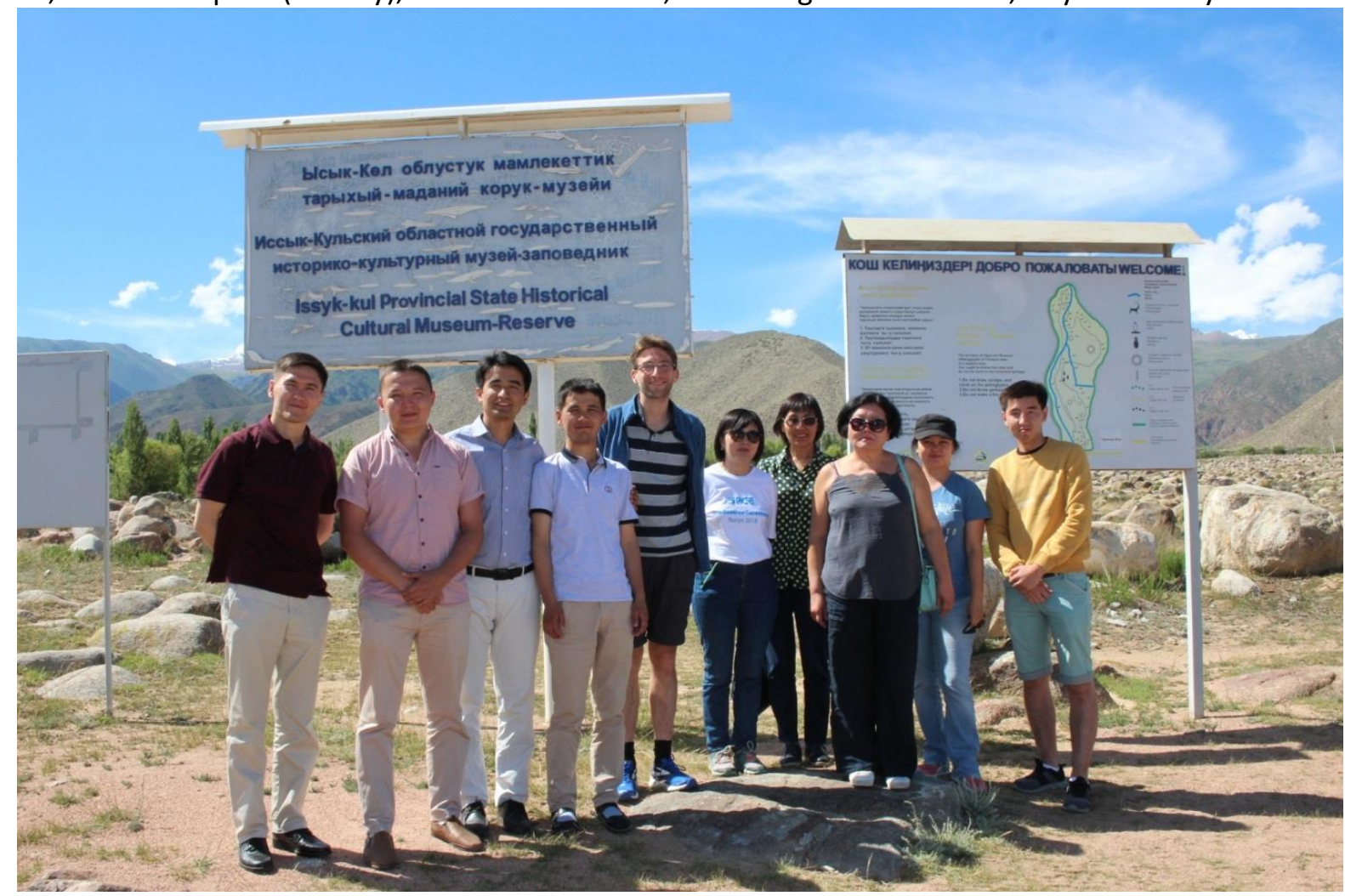

Figure 5. Issyk-Kul Provincial State Historical Cultural Museum-Reserve:Kudaibergen Osmonaliev, Adylbek Shadykanov, Nurlan Torokeldiev, Damirbek Abibillaev, Jonathan Lipton (Faculty), Nuraim Zhakybalieva, Zhenisgul Tlegenova, Gulmira Kudaiberdieva(Faculty), Aiperi Toktosunova,Daniyar Cholponbaev. 


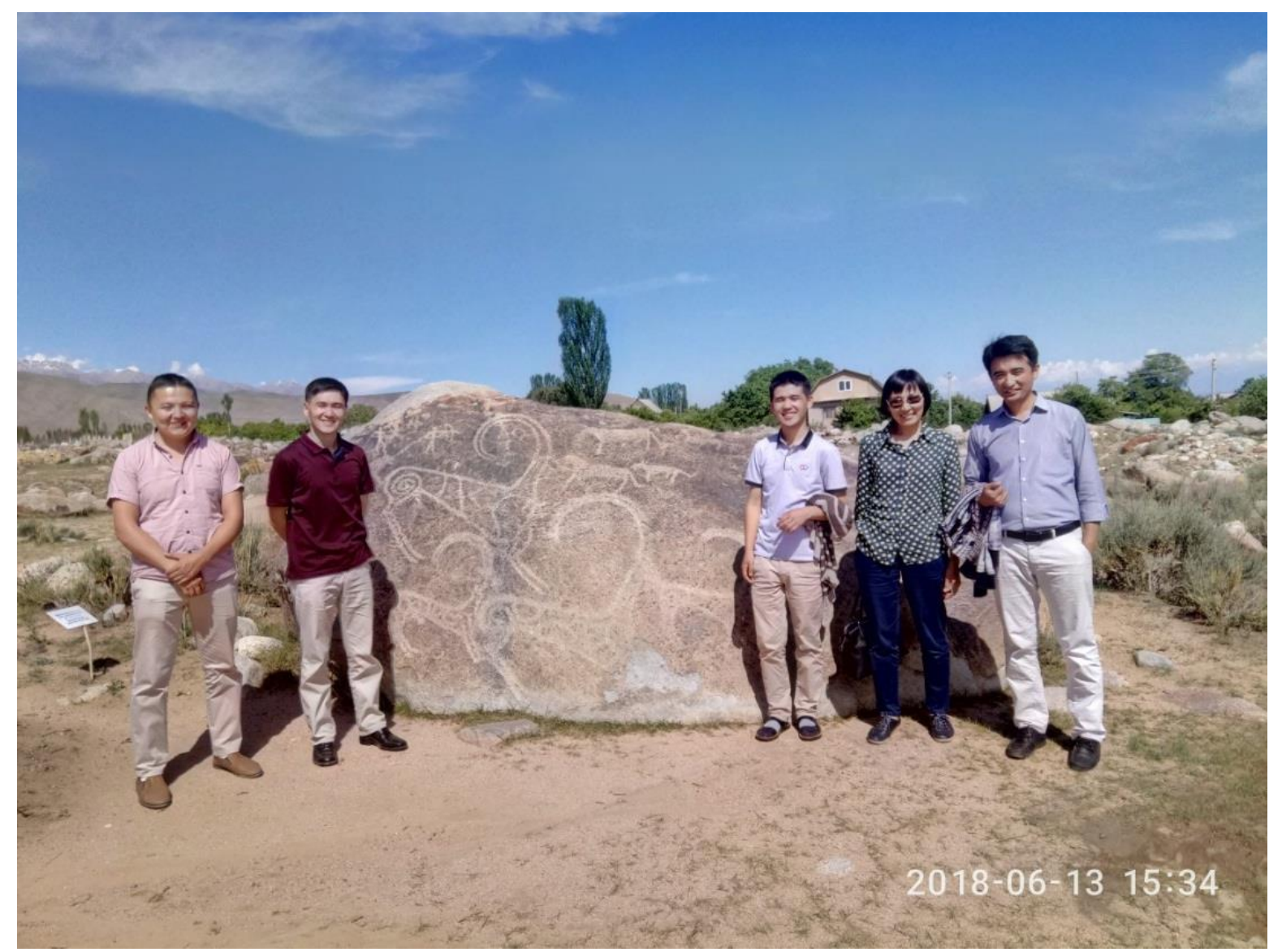

Figure 6. Cholpon-Ata, Petroglyphs: Adylbek Shadykanov,Kudaibergen Osmonaliev, Damirbek Abibillaev, Zhenisgul Tlegenova, Nurlan Torokeldiev.

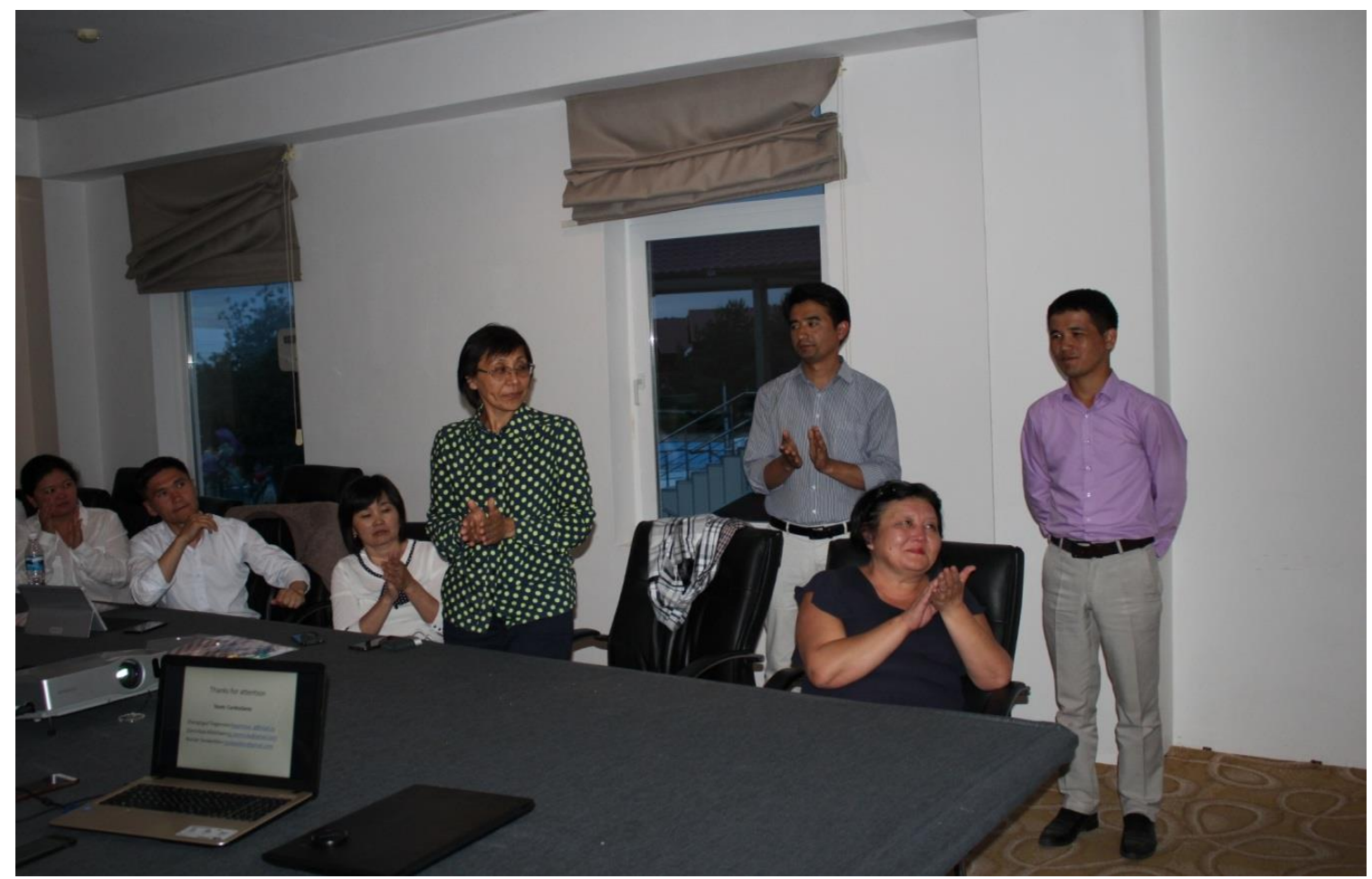

Figure 7. CardioGene Team, final presentation: Aiperi Toktosunova, Kudaibergen Osmonaliev, Nuraim Zhakybalieva, Zhenisgul Tlegenova, Nurlan Torokeldiev, Gulmira Kudaiberdieva (Faculty), Damirbek Abibillaev 


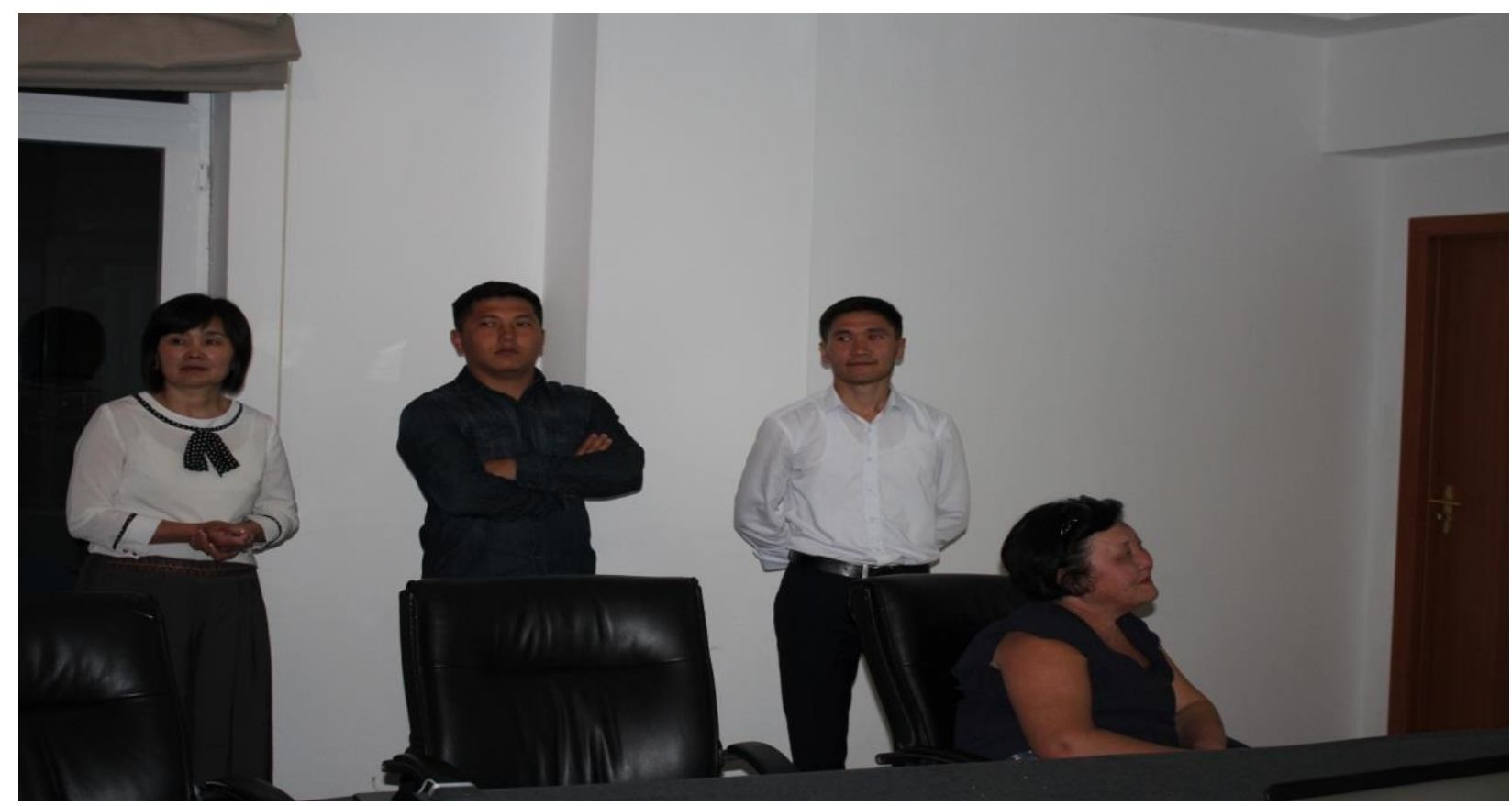

Figure 8. Jailoo and Saamal Team, final presentation: Nuraim Zhakybalieva, Kairat Nurbekov, Kudaibergen Osmonaliev and Gulmira Kudaiberdieva (Faculty)

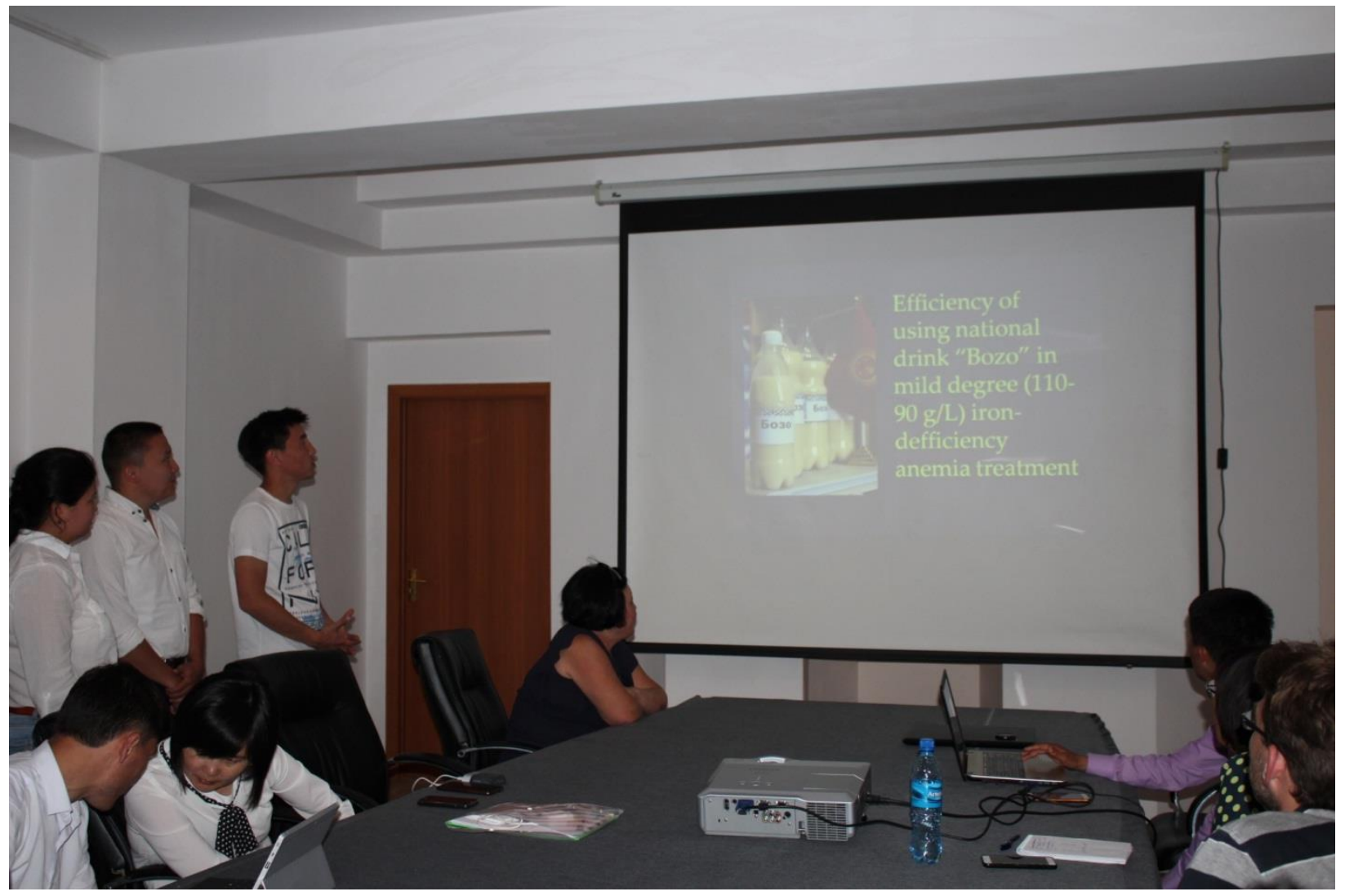

Figure 9. BOZO Team, final presentation: Aiperi Toktosunova, Adylbek Shadykanov, Daniyar Cholponbaev, sit on the left side: Kudaibergen Osmonaliev, Nuraim Zhakybalieva, Gulmira Kudaiberdieva (Faculty), sit on the right side: Jonathan Lipton (Faculty), Zhenisgul Tlegenova, Damirbek Abibillaev 
Although the teams worked from early morning until late at night, but the organizers took the time to visit the Petroglyphs of Cholpon Ata. Petroglyphs in Cholpon -Ata date back to the two thousand (A.D.). The surface of the stones under the influence of sunlight was covered with a "desert tan". "Tanning stones" served as a canvas for ancient artists. Among the drawings, images of animals predominate: goats, deer, dogs and horsemen.

One day there was an additional discussion with the editors of the journals, how to write the manuscript, how to choose the right journal, how to handle the peer-review comments, how to communicate with the editor.

The school ended with the final presentation of projects and the delivery of certificates. Below are the comments of the school participants.

Damirbek Abibillaev: As an initial step to research work it is an invaluable issue participating in IRIS. Every action is carried out by tremendous work and serious attendance of course with so many obstacles. If you are guided by professionals then you feel yourself quietly motivated, supported, endorsed. After summer school I can definitely advise to everyone who wants to be involved in research projects to join for IRIS program.

Kudaibergen Osmonaliev: Reading and understanding a scientific book is hard thing. After reading and understanding application of that knowledge is another problem for scientific people, especially if they are beginners. This workshop program gives us all these things together at once. In my opinion, the workshop was very effective. Because in short period of time we learned and applied our knowledge. Other important thing we found new friends from different regions of our country and international collaborators. I want thank organizers for this great workshop program and I wish they will continue organizing these programs and be helpful for scientists.

Zhenisgul Tlegenova: This is my second IRIS school. The knowledge and experience that I received from previous IRIS in Astana helped me to start my own research project. This school has very high level of training standards and practical direction that give chance to finish research project in a short time. During additional session the faculty communicated with participants on how to write manuscript and publish it in an international peer-reviewed journal. It helped us to write our own manuscripts. The Faculty is very friendship, rapid introduction to the course, new collaboration, new ambitious colleagues and very nice nature to motivate me recommend the IRIS school to all beginner researchers.

Adylbek Sadykanov: IRIS is a great opportunity for doctors, for specialists from different fields to cooperate. This trainings effectively helps to novice researchers deeply understand how research works carried out. Answers can be taken to the questions you are interested in. Working in a group of creative, talented people from different countries, you are encouraged to do the science.

Aiperi Toktosunova: the participation in this school gave me very useful skills. It is my first time in such project. But I have only good emotions here. It was very excited to take part with high educational level teachers. In 5 days they give us not only information how to write the manuscript, but give the inspiration to continue my scientific way. I hope that we will meet in the future again. Thanks for all members: participants and teachers.

Nurlan Torokeldiev: IRIS was well organized with several workshops based on how to structure research projects in medical and non-medical investigations. Additionally, the program offered short course on how to write a manuscript and deal with post-submission process. First of all, I would like to gratitude my thanks to Gulmira and Jonathan on their excellent supervisions during the program. I have lots of purposes for being thankful. Frankly, even holding an internal PhD degree I have learnt a lot of skills on critical thinking and formulating scientific projects. Therefore, I plan to write my own scientific project and apply for grant funding. Besides, a course on writing a manuscript has broadened my skills during peer-review process of several scientific journals. For future collaborative projects IRIS definitely opens several opportunities. Besides, participants always have chances to start both local and international networking among multidisciplinary institutions. I would definitely recommend and encourage medical doctors, scientists and scholars from any disciplines all around the world to experience world-class workshops and courses. On behalf of my IRIS 2018 participants, I would like to express my thanks and hope to take in place in the next IRIS events. 
Danyar Cholponbaev: We worked hard these 5 days. I was happy to take a part at this summer school. I want to thanks every participant and faculty for this. It's very good experience for me, that I met new people, new communications and I knew something new for me. I'll be happy to take a part in IRIS again.

Kairat Nurbekov: It was a great pleasure to participate in IRIS school. Definitely, it was most memorable event of this summer. For the time spent here, I learned a lot: how to create my own research project, what details to pay attention to. In addition, the school helps develop critical thinking and teamwork skills. All this is thanks to a non-standard form of training, which in my opinion has several advantages over the standard way of teaching.
Besides the main tasks, this school helps to get to know many interesting people and make new friends. These days have left in my memory exceptionally warm memories. Thanks for a great time.

Nurayim Zhakybalieva: First of all I want to thank Jonathan and Gulmira for organization of this program, especially in our country. I was very impressed, because I did not have such kind of program and I learned many things in a short period of time. Workshops were very interesting, especially self-study brainstorms. In addition, I found new friends for collaboration. Thanks for recommendations for our future work.

Next IRIS school will be held in Slovakia in 2019. 


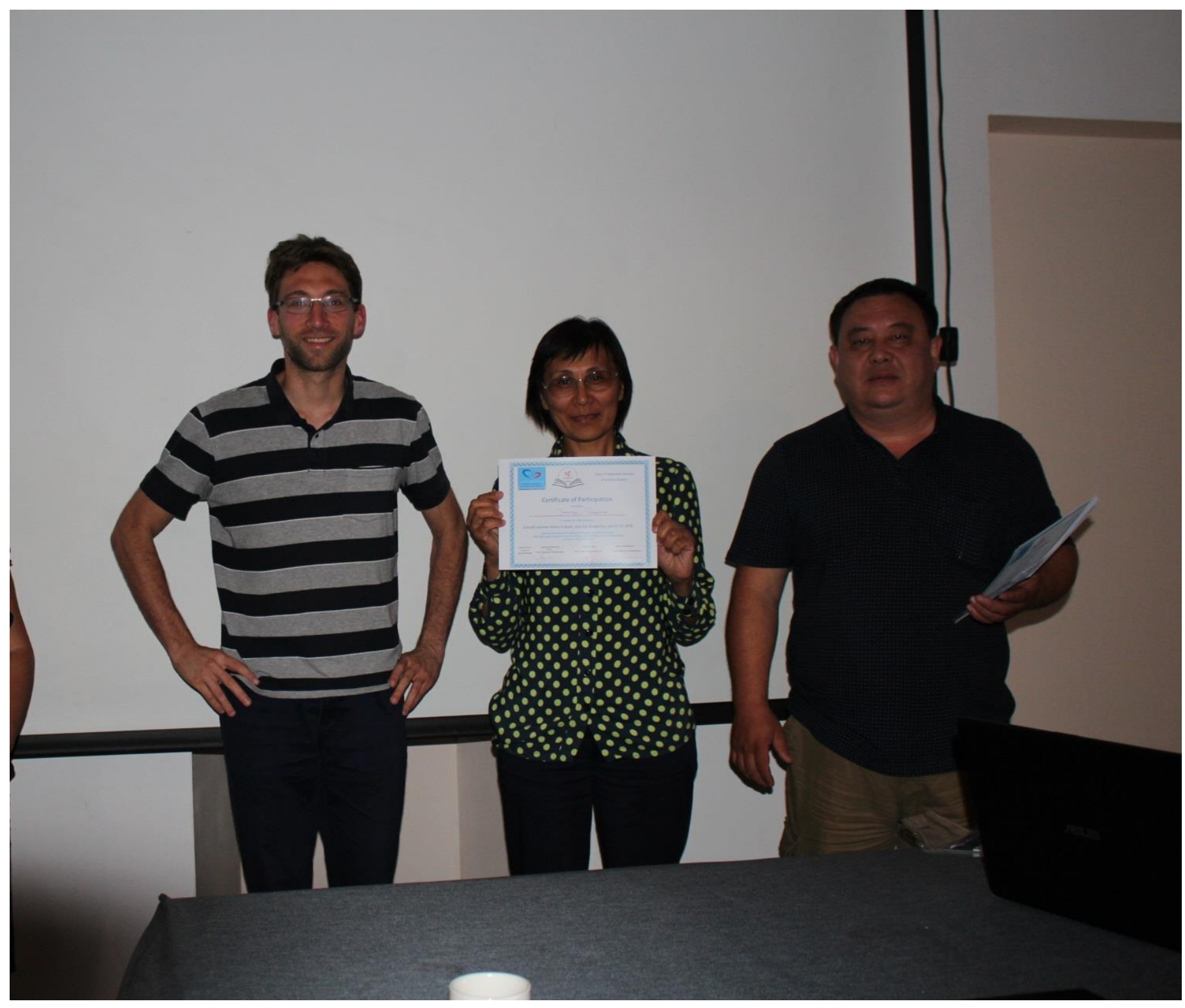

Figure 10. Award Ceremony: Jonathan Lipton, Zhenisgul Tlegenova, Taalaibek Kudaiberdiev, 